\title{
Long Term Rainfall Trend Using High Resolution Gridded Data over the West Coast of Karnataka, India
}

\author{
Vinay Doranalu $\mathrm{C}^{1^{*}}$, Amba Shetty ${ }^{1}$ and Gebremedhin Kiros ${ }^{1}$
}

\begin{abstract}
A $0.25^{\circ} \times 0.25^{\circ}$ high resolution gridded dataset of daily observed rainfall is analyzed to study long term spatial and temporal trends on annual scales in west coast of Karnataka, located in west coast of India during 1901-2013. After testing the homogeneity for entire data set the monotonic two tailed Mann-Kendall test analysis is applied for the time series data to detect the trends in rainfall. Theil and Sen's slope estimator test is used for finding the magnitude of change over a time period. The rainfall time series is divided in to four periods with the hydrological cycle of thirty years for finding the changes in trends with change in period. Most of the grid points shows a significant increase in trend in annual rainfall during 1901-2013. Rainfall is changing most significantly for every hydrological cycle.
\end{abstract}

Keywords - Gridded data, India, Mann-Kendall Trend Analysis, Rainfall, West coast.

\section{INTRODUCTION}

Understanding of the spatio-temporal variability rainfall have an important role for the human life on Earth. Accurate estimation of rainfall is required to assess water resources, potential the measurement of rainfall intensity, frequency and duration is also important to understand the trend of rainfall and to forecast the hazards caused by intense rain.

Rainfall is a highly dynamic phenomenon and changing its intensity, frequency and duration with influence of topographical parameters such as elevation, vegetation (forest), land use cover, anthropogenic activity and many more factors. In west coast of India, coastal region of Karnataka is one of the main centers of action of intense rainfall [1]. In particularly the coastal region of Karnataka, exhibits a high spatial and temporal variability of rainfall and which is on the wind ward side of the mountain range and thick forest (vegetation) of Western Ghats. Generally this region receives heavy rainfall due to orographic effect [2]. $90 \%$ of the rainfall drains the region by losing moisture content carried from Arabian Sea

Manuscript received February. 19, 2016.

Vinay Doranalu C, Ph.D. Scholar, Department of Applied Mechanics \& Hydraulics, National Institute of Technology Karnataka, Surathkal, Mangalore 575025, India

Amba Shetty, Associate Professor, Department of Applied Mechanics \& Hydraulics, National Institute of Technology Karnataka, Surathkal, Mangalore 575025, India

Gebremedhin Kiros, Ph.D. Scholar, Department of Applied Mechanics \& Hydraulics, National Institute of Technology Karnataka, Surathkal, Mangalore 575025, India during southwest monsoon season. In, general the interface of sea/land receives intense rainfall and it decreases considerably as moves towards in land region. The extent of high elevation is well spread in coastal Karnataka, India. The analysis of variability in elevation in the context of spatial distributions of rainfall infers that, increment in elevation intensifies rainfall and rainfall declines before it confront summit barrier [3].

Within the monsoon season from June to September (JJAS), intra-seasonal trend of rainfall over coastline region fluctuates between active spells with heavy rainfall and weak spells with little or no rainfall. Daily rainfall exceeding $150 \mathrm{~mm}$ over coast is one of the major challenges for normal activity [4]. The trend of intense rainfall over the coastline is generally attributed to the stable ascent of moist air from the Arabian Sea over the orography of the Western Ghats [5]. Mountain ranges can also act as elevated heat sources and hence low-pressure region, which induces convergence of air and hence uplifting [6]. Depending on the thermodynamic and dynamic structure in the mid-troposphere, deep convection could be initiated by away from the Western Ghats to shoreline. On several times it can be noticed that, weather stations near coastline record high rainfall than the stations over the Western Ghats [7]. It is suggested that, intense rainfall events are associated with offshore troughs and/or offshore vertices [8]. The purpose of this study is to understand the monotonic trend of rainfall in the coastal region and analyze statistically weather trend is there or not.

\section{STUDY AREA AND METHODOLOGY}

Coastal region of Karnataka state situated in between $12^{\circ} 30^{\prime}$ North latitude $74^{\circ} 00^{\prime} \mathrm{E}$ longitude and $15^{\circ} 00^{\prime} \mathrm{N}$ latitude $75^{\circ} 30^{\prime}$ E longitude. It has been observed that the Western Ghats runs parallel to the Coastline of Karnataka. The coastal strip of Karnataka, called Karavalli, between the Western Ghats and the Arabian Sea, which is lowland region, which receives moderate to intense rainfall. This strip is around $320 \mathrm{~km}$ in length and 48-64 km wide. The Western Ghats, called Malenadu, a mountain range inland from the Arabian Sea, rising to about $900 \mathrm{~m}$ average height, and with moderate to high rainfall levels. Fig. 1 shows the location and the selected grid points (GP) of the study area, using $0.25^{\circ} \times 0.25^{\circ}$ of daily observed rainfall of IMD Gridded data for 1901 to 2013 time periods. The 17 grid points are selected based on the location situated in wind ward side of the Western Ghats of Karnataka. 
Due to heavy rainfall over Western Ghats, are giving birth to many rivers and flows towards the Arabian sea (West side) and
East side. Those rivers which flow towards west are familiar as 'west flowing rivers'.

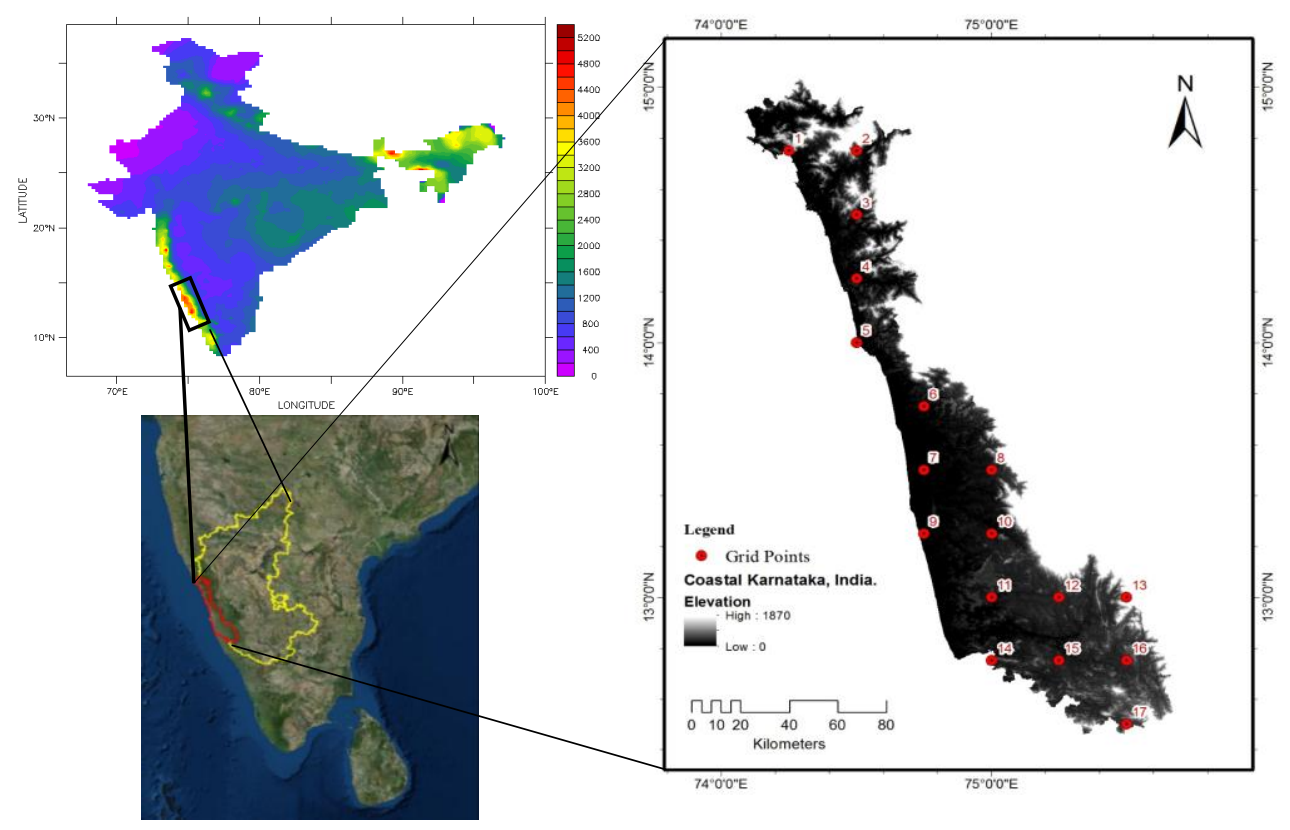

Fig. 1. Geographic location of the coastal region of Karnataka

\section{A. Mann-Kendall Trend Analysis}

Non-parametric Mann-Kendall test a statistical procedure that is sound matched for analyzing trends in data over time. Any assumptions as to the statistical normally distribution of the data does not require for the Mann-Kendall test (e.g., normal, lognormal, etc.,) and can be used with data sets which include missing data and irregular sampling intervals [9-11]. This method was applied for the temporally distributed hydro-meteorological data trends at $95 \%$ level of significance. Though the performance of the test can be adversely affected, the Mann-Kendall test can be computed if there are missing values and values below one or more limits of detection. Assumption of independence requires that the time between samples be sufficiently large so that there is no correlation between measurements collected at different times [12].

The procedure to compute for the Mann Kendall test considers the time series of $\mathrm{n}$ data points and $\mathrm{Xk}$ and $\mathrm{Xj}$ as two subsets of data where $\mathrm{k}=1,2,3, \ldots, \mathrm{n}-1$ and $\mathrm{j}=\mathrm{k}+1, \mathrm{k}+2$, $\mathrm{k}+3, \ldots, \mathrm{n}$. The data values as an ordered time series are evaluated. Each data value is compared with all subsequent data values. The statistic $S$ is incremented by one, if a data value from a later time period is higher than a data value from an earlier time period. On the other hand, $S$ is decremented by 1 , if the data value from a later time period is lower than a data value sampled earlier. The net result of all such increase and decrease yields the final value of $S$ [13].

Therefore, the Mann-Kendall S Statistic trend test for a time series is computed as follows:

$$
\begin{gathered}
S=\sum_{k=1}^{n-1} \sum_{j=k+1}^{n} \operatorname{sign}\left(X_{j}-X_{k}\right) \\
\operatorname{Sign}\left(X_{j}-X_{k}\right)=\left\{\begin{array}{l}
+\operatorname{lif}\left(X_{j}-X_{k}\right)>0 \\
0 i f\left(X_{j}-X_{k}\right)=0 \\
-1 i f\left(X_{j}-X_{k}\right)<0
\end{array}\right\}
\end{gathered}
$$

Where $\mathrm{Xj}$ and $\mathrm{Xk}$ are the annual values in years $\mathrm{j}$ and $\mathrm{k}, \mathrm{j}>\mathrm{k}$, respectively [14] as can be seen from the equation (2). The test statistic depends not on their actual values resulting in a distribution free test statistic rather on the ranks of the observations, because for any distribution, the ranks remain the same.

If $\mathrm{n}<10$, the value of $|S|$ is compared directly to the theoretical distribution of S which is derived by the Mann and Kendall. The two tailed test is used. At certain probability level $\mathrm{H} 0$ is rejected in favor of $\mathrm{H} 1$ if the absolute value of $\mathrm{S}$ equals or exceeds a specified value $S \alpha / 2$, where $S \alpha / 2$ is the smallest $S$ which has the probability less than $\alpha / 2$ to appear in case of no trend. A positive (negative) value of $\mathrm{S}$ indicates an upward (downward) trend [13].

For $\mathrm{n} \geq 10$, the statistic $S$ is approximately normally distributed with the mean and variance as follows [10]:

$$
\begin{gathered}
E(S)=0 \\
\operatorname{Var}(S)=\frac{n(n-1)(2 n+5)}{18}
\end{gathered}
$$


Where $\mathrm{n}$ is the number of observations. The existence of tied ranks (equal observations) in the data results in a reduction of the variance var $(\mathrm{S})$ for the $\mathrm{S}$-statistic is defined by:

$$
\operatorname{Var}(S)=\frac{n(n-1)(2 n+5)-\sum_{p-1}^{q} t_{p}\left(t_{p}-1\right)\left(2 t_{p}+5\right)}{18}
$$

Where tp is the number of ties for the pth value and $q$ is the number of tied values this means the summation term in the numerator is used only if the data series contains tied values. The standardized test statistic Zs is calculated as follows [11].

$$
Z=\left\{\begin{array}{l}
\frac{S-1}{\sqrt{\operatorname{Var}(S)}} \text { if } S>0 \\
0 i f S=0 \\
\frac{S+1}{\sqrt{\operatorname{Var}(S)}} \text { if }<<0
\end{array}\right\}
$$

The test statistic Zs is used a measure of significance of trend. In fact, this test statistic is used to test the null hypothesis, H0. If $|\mathrm{Zs}|$ is greater than $\mathrm{Z} \alpha / 2$, where $\alpha$ represents the chosen significance level (e.g. $5 \%$ with $\mathrm{Z} 0.025=1.96$ ) then the null hypothesis is invalid implying that the trend is significant [14].

The linear slopes where the magnitudes of trends are calculated using the Thiel-Sen approach (TSA) [15][16]. The TSA slope $\beta$ is given by:

$$
\beta=\operatorname{Median}\left[\frac{X_{j}-X_{k}}{j-k}\right] \text { for all } \mathrm{k}<\mathrm{j}
$$

Where $\mathrm{Yk}$ and $\mathrm{Yj}$ are data at time points $\mathrm{k}$ and $\mathrm{j}$, respectively. If the total number of data points in the series is $n$, then there will be $\frac{n(n-1)}{2}$ slope estimates and the test statistic $\beta$ Sen is the median of all slope estimates. Positive and negative sign of test statistics indicate increasing and decreasing trends respectively. For performing the statistical Mann-Kendall test software Addinsoft's XLSTAT 2015 is applied for rainfall data of 17 grid points in the study area, the null hypothesis is tested at $95 \%$ confidence level. Besides, to compare the results obtained from the Mann-Kendall test, linear trend lines are plotted for each grid points.

\section{RESUlTS AND DisCUSSION}

\section{A. Spatial variability of Rainfall}

The Spatial variations of rainfall which range maximum near shoreline, and decreases considerably as moves towards inland region. The average annual rainfall estimated from 1901 to 2013 records indicated that rainfall over the coastal region (i.e., grid points from 1 to 17 ) is $3961 \mathrm{~mm}$, Fig. 2 Shows the uneven distribution of annual rainfall with increasing trend over the study period (1901-2013).

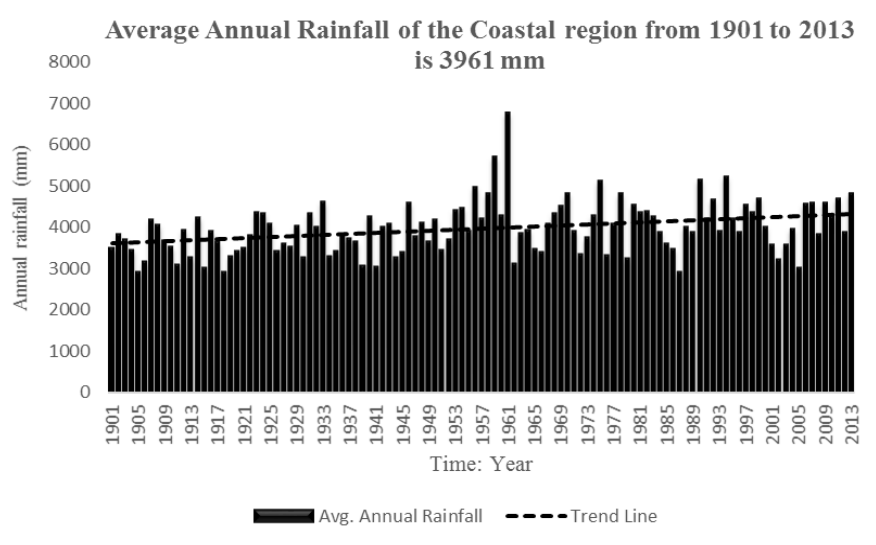

Fig. 2. Average annual rainfall of Coastline region

Rainfall in the coastal region is characterized by high inter-annual variability as the rainfall over tropical wet and dry areas exhibits such variability.

TABLE I: ANNUAL STATISTICAL RAINFALL (MM) AND THEIR COEFFICIENT OF VARIATION OF GRID POINTS

\begin{tabular}{cccccc}
\hline $\begin{array}{c}\text { Grid } \\
\text { Points }\end{array}$ & Min & Max & Mean & $\begin{array}{c}\text { Std. } \\
\text { deviation }\end{array}$ & CV\% \\
\hline 1 & 2027.64 & 5559.87 & 3441.74 & 580.77 & 16.87 \\
2 & 1800.29 & 5702.83 & 3036.38 & 753.36 & 24.81 \\
3 & 2140.79 & 8816.94 & 3925.14 & 1390.86 & 35.43 \\
4 & 1964.41 & 6620.96 & 3864.01 & 780.99 & 20.21 \\
5 & 2714.47 & 7012.59 & 4185.55 & 724.55 & 17.31 \\
6 & 2181.05 & 9650.95 & 4433.24 & 1306.11 & 29.46 \\
7 & 2506.34 & 7987.72 & 4496.33 & 1033.80 & 22.99 \\
8 & 1793.31 & 9792.77 & 4155.10 & 1880.95 & 45.27 \\
9 & 2438.18 & 6534.10 & 4318.84 & 737.74 & 17.08 \\
10 & 1819.78 & 6591.57 & 4226.93 & 927.72 & 21.95 \\
11 & 2304.81 & 6543.31 & 4219.99 & 649.84 & 15.40 \\
12 & 1938.99 & 7500.56 & 4165.29 & 696.26 & 16.72 \\
13 & 1853.25 & 5970.41 & 3819.21 & 716.55 & 18.76 \\
14 & 2233.22 & 6999.33 & 3987.03 & 627.70 & 15.74 \\
15 & 2011.72 & 7217.72 & 4190.69 & 689.32 & 16.45 \\
16 & 1160.90 & 5634.92 & 2281.59 & 614.64 & 26.94 \\
17 & 1853.25 & 5970.41 & 3819.21 & 716.55 & 18.76 \\
\hline
\end{tabular}

The annual rainfall coefficient of variation $(\mathrm{CV})$ of the grid points in the coastal region ranging from relatively a minimum of $15.74 \%$ to a maximum of $45.27 \%$ (see Table I). Due to the difference between minimum and maximum values of the grid pints are low and high respectively. Less the variability more the consistent average rainfall could expect.

\section{B. Rainfall intensity and frequency indices}

Generally any discussion on changes to extreme of rainfall begins with changes of total annual rainfall (PRCPTOT) index at local and regional levels. This is probably the most important parameter reflecting rainfall variations over the entire study period which is one among various rainfall indices scanned in this study. Positive trends are observed in PRCPTOT occurred in the grid points 1 to 17 . 
However, most of the grid points show statically significant with increasing trend at $5 \%$ significance level, the GP's 11,12 , 13, 15, 16 and 17 are showed decreasing trend rainfall insignificantly ranging from $1.8 \mathrm{~mm} / \mathrm{y}$ to $7.71 \mathrm{~mm} /$ year, only the grid point 10 is shown significantly decreasing trend of $7.71 \mathrm{~mm} /$ year for the period 1901-2013 (see Table: II).

\begin{tabular}{ccccccc}
\multicolumn{2}{c}{ TABLE II: MANN-KENDALL STATISTICS FOR PRCPTOT, CDD AND CWD } \\
\hline \multirow{2}{*}{ GP } & \multicolumn{2}{c}{ PRCPTOT (mm/y) } & \multicolumn{2}{c}{ CDD (days/y) } & \multicolumn{2}{c}{ CWD (days/y) } \\
\cline { 2 - 7 } & P-Value & $\begin{array}{c}\text { Sen's } \\
\text { slope }\end{array}$ & P-Value & $\begin{array}{c}\text { Sen's } \\
\text { Slope }\end{array}$ & P-Value & $\begin{array}{c}\text { Sen's } \\
\text { Slope }\end{array}$ \\
\hline 1 & 0.02 & 3.81 & 0.02 & -0.07 & 0.02 & 0.08 \\
2 & $<0.0001$ & 10.40 & 0.00 & 0.11 & 0.00 & -0.11 \\
3 & $<0.0001$ & 20.60 & 0.58 & -0.02 & 0.57 & 0.02 \\
4 & $<0.0001$ & 10.73 & 0.01 & 0.10 & 0.01 & -0.10 \\
5 & $<0.0001$ & 8.45 & 0.01 & -0.09 & 0.01 & 0.10 \\
6 & $<0.0001$ & 16.74 & 0.13 & -0.06 & 0.11 & 0.06 \\
7 & $<0.0001$ & 13.80 & 0.33 & -0.04 & 0.33 & 0.04 \\
8 & 0.86 & 0.44 & 0.01 & -0.10 & 0.01 & 0.10 \\
9 & 0.08 & 3.91 & 0.47 & -0.03 & 0.42 & 0.03 \\
10 & 0.01 & -7.71 & 0.19 & -0.05 & 0.18 & 0.05 \\
11 & 0.37 & -1.67 & 0.19 & 0.05 & 0.20 & -0.04 \\
12 & 0.28 & -1.80 & 0.39 & -0.03 & 0.38 & 0.03 \\
13 & 0.66 & -0.66 & 0.02 & 0.11 & 0.02 & -0.11 \\
14 & 0.21 & 2.03 & 0.00 & -0.15 & 0.00 & 0.15 \\
15 & 0.72 & -0.73 & 0.64 & 0.02 & 0.65 & -0.01 \\
16 & 0.83 & -0.44 & $<0.0001$ & 0.18 & $<0.0001$ & -0.18 \\
17 & 0.83 & -0.44 & $<0.0001$ & 0.18 & $<0.0001$ & -0.18 \\
\hline
\end{tabular}

A measure change to drier conditions amongst the indices is the Consecutive Dry Day (CDD) Index. Results of trend magnitudes (days/year) for stations with increasing and decreasing trends to CDD and CWD at $\alpha=0.05$ significant level are shown in Table II for the coastal region. For the period of 1901-2013, annual rainfall shows significantly decreasing trends of the Consecutive Dry Days index detected for GP's 1, 5,8 , and 14 (ranging from 0.07 to 0.15 days/year) in the coastal region. The negative trends in annual rainfall at other grid points are also somehow low, though statistically not significant at 0.05 level of significance due to large inter annual fluctuations. CDD is the measure of dryness; Consecutive Wet Days index (CWD) is the measure of wetness, on the contrary, reveals the time series variations that can direct to wetter conditions. For the study period 1901-2013 there is no much change in wet days and dry period.

\section{Shift in annual rainfall for the hydrological cycle}

In the period 1901-1930, most of the grid points are insignificantly increase or decrease trend with less variation upto $34 \mathrm{~mm} /$ year and $-6.69 \mathrm{~mm} /$ year in the coastal region, respectively. During 1931-1960 time period, there is a significantly high increase in rainfall in the grid points of the coastal region upto $102 \mathrm{~mm} /$ year. In the study area high value of significantly increasing and decreasing trend upto 87.18 $\mathrm{mm} /$ year and $-140 \mathrm{~mm} /$ year, respectively were noticed in the 1961 to 1990 time period. Finally in the last hydrological cycle (1901-2013) showing drastically changed in rainfall in the region where many grid points showing significantly decreasing trend upto $-107.27 \mathrm{~mm} /$ year. However, few grid points were significantly increasing trend $79.34 \mathrm{~mm} /$ year Sen's slopes magnitude (see Table III). Therefore, comparing the four hydrological cycles, except the first cycle all the others showed more variation in rainfall in the coastal region.

\begin{tabular}{|c|c|c|c|c|c|c|c|c|}
\hline \multirow[b]{2}{*}{ GP } & \multicolumn{2}{|c|}{$1901-1930$} & \multicolumn{2}{|c|}{$1931-1960$} & \multicolumn{2}{|c|}{ 1961-1990 } & \multicolumn{2}{|c|}{$1901-2013$} \\
\hline & $\mathrm{P}$-value & $\begin{array}{l}\text { Sen's } \\
\text { Slope }\end{array}$ & $\mathrm{P}$-value & $\begin{array}{l}\text { Sen's } \\
\text { Slope }\end{array}$ & $\mathrm{P}$-value & $\begin{array}{l}\text { Sen's } \\
\text { Slope }\end{array}$ & $\mathrm{P}$-value & Sen's Slope \\
\hline 1 & 0.58 & -2.31 & 0.10 & 25.39 & 0.16 & 22.08 & 0.18 & 22.32 \\
\hline 2 & 0.73 & 3.58 & 0.33 & 9.23 & 0.60 & 9.64 & 0.33 & -32.19 \\
\hline 3 & 0.79 & -4.56 & 0.51 & 9.25 & $\mathbf{0 . 0 0} * *$ & 87.18 & $0.01 * *$ & -107.27 \\
\hline 4 & 0.84 & 2.39 & 0.06 & 28.84 & $0.07 *$ & 30.58 & 0.28 & 23.96 \\
\hline 5 & 0.96 & 0.33 & 0.12 & 22.64 & 0.44 & 5.84 & 0.89 & -4.19 \\
\hline 6 & 0.73 & 2.71 & $<0.0001 * *$ & 102.36 & 0.84 & 2.65 & 0.12 & 42.47 \\
\hline 7 & 0.96 & -0.58 & $<0.0001 * *$ & 75.64 & $0.08 *$ & -40.55 & $0.04 * *$ & 50.42 \\
\hline 8 & 0.84 & -1.35 & $0.02 * *$ & 91.08 & $0.00 * *$ & -140.68 & $0.04 * *$ & 79.34 \\
\hline 9 & 0.99 & -0.43 & 0.22 & 19.25 & 0.18 & -28.67 & 0.44 & -16.25 \\
\hline 10 & 0.99 & 0.80 & 0.31 & 17.14 & 0.10 & -45.09 & 0.58 & 30.52 \\
\hline 11 & 0.79 & 2.54 & 0.87 & 2.30 & 0.38 & -13.88 & $0.06 *$ & -37.12 \\
\hline 12 & 0.63 & 5.44 & 0.34 & 10.78 & 0.56 & -6.48 & 0.13 & -33.81 \\
\hline 13 & 0.84 & 1.95 & 0.10 & 25.54 & 0.58 & 7.20 & 0.48 & 7.89 \\
\hline 14 & 0.40 & 7.13 & 0.87 & -2.82 & 0.10 & -21.41 & 0.28 & -18.42 \\
\hline 15 & 0.10 & 16.13 & 0.31 & 12.84 & 0.60 & -11.70 & $0.00 * *$ & -66.37 \\
\hline 16 & $0.01 * *$ & 34.35 & 0.76 & 3.19 & 0.63 & 10.09 & $0.05 *$ & -37.56 \\
\hline 17 & $0.01 * *$ & 34.35 & 0.76 & 3.19 & 0.63 & 10.09 & $0.05 *$ & -37.56 \\
\hline
\end{tabular}

(*) means significant at $\mathrm{p}<0.1$ and $(* *)$ means significant at $\mathrm{p}<0.05$ 


\section{CONCLUSION}

The annual rainfall variability of the grid points in the coastal region ranging from relatively a minimum of $15.74 \%$ to a maximum of $45.27 \%$ as a result the difference between minimum and maximum values of the grid pints are low and high respectively. Less the variability more the consistent average rainfall could be highlighted. Rainfall in the coastal region is characterized by high inter-annual variability as the rainfall over tropical wet and dry areas exhibit such variability. Grid points which received relatively less mean rainfall showed high variability in annual rainfall. A reversal scenario in grid points received high mean rainfall noticed low variability in annual rainfall. In the low land region total annual precipitation, wet days and dry days have shown significantly increasing and decreasing trend and showed a higher Sen's slope magnitude specifically the CWD and CDD indicated that almost equal but opposite values of Sen's slope magnitude. Comparing the four hydrological cycles, except the first cycle all the others showed more variation in rainfall in the coastal region.

\section{REFERENCES}

[1] M. Mohanty, K. Ray, and K. Chakravarthy, High-Impact Weather Events over the SAARC Region, Springer International Publishing, 2015, pp. 259-276.

[2] M. K. Soman, and K. K. Kumar, "some aspects of daily rainfall distribution over India during the south-west monsoon season," International Journal of Climatology, vol. 10, pp. 299-311, April 1990.

[3] S. A. Tawde and C. Singh, "Investigation of orographic features influencing spatial distribution of rainfall over the Western Ghats of India using satellite data," International Journal of Climatology, vol. 35, pp. 2280-2293, July 2015.

[4] P. A. Francis, and Sulochana Gadgil, "Intense rainfall events over the west coast of India," Meteorology and Atmospheric Physics, vol. 94, pp. 27-42, 2006.

[5] Y. Oruga, M. Yoshizaki, "Numerical study of orographic-convective precipitation over eastern Arabian Sea and the Ghat mountains during the summer monsoon," Journal of the atmospheric sciences, vol. 45, pp, 2097-2121, 1988

[6] H. D. Orville, "Ambient wind effects on the initiation and development of cumulus clouds over mountains," Journal of the Atmospheric Sciences, vol. 25, pp. 385-403, 1968

[7] A. K. Mukherjee, (1980). "Dimension of an offshore vortex in East Arabian Sea as deduced from observations during MONEX 1979: FGGE Operations Report. Geneva: World Meteorological Organization, vol. 9.

[8] V. Srinivasan, "Discussion of typical synoptic situation over Konkan and coastal Karnataka," India Meteorological Department Forecasting Manual III, Vol. 3, 1972.

[9] H. B. Mann, "Nonparametric tests against trend," Econometrica: Journal of the Econometric Society, vol. 13, pp. 245-259, July 1945.

[10] M. Kendall, Multivariate analysis. Charles Griffin, 1975.

[11] R. O. Gilbert, Statistical methods for environmental pollution monitoring, John Wiley \& Sons, 1987.

[12] R. M. Hirsch, J. R. Slack, and R. A. Smith, "Techniques of trend analysis for monthly water quality data," Water resources research, vol. 18, pp. 107-121, February 1982.

[13] K.Drápela, and I. Drápelová, "Application of Mann-Kendall test and the Sen's slope estimates for trend detection in deposition data from Bílý Kříž (Beskydy Mts., the Czech Republic) 1997-2010," Beskydy, vol. 4, pp. 133-146, 2011.
[14] H. Motiee, and E. McBean, "An assessment of long-term trends in hydrologic components and implications for water levels in Lake Superior," Hydrology Research, vol. 40, pp. 564-579, 2009.

[15] P. K. Sen, "Estimates of the regression coefficient based on Kendall's tau," Journal of the American Statistical Association, vol. 63, pp. $1379-1389,1968$

[16] H. Thiel, (1950). "A rank-invariant method of linear and polynomial regression analysis, Part 3," Proceedings of Koninalijke Nederlandse Akademie van Weinenschatpen, pp. 1397-1412, vol. 53 